\title{
A Novel and Simple Route to Synthesis Nanocrystalline Titanium Carbide via the Reaction of Titanium Dioxide and Different Carbon Source
}

\author{
Youjian Chen ${ }^{1}$, Yongyong Deng' ${ }^{1}$ Hong Zhang ${ }^{1}$, Lihua Wang ${ }^{3}$, Jianhua Ma $^{1,2^{*}}$ \\ ${ }^{1}$ College of Chemistry and Materials Engineering, Wenzhou University, Wenzhou, China; ${ }^{2}$ Nanomaterials and Chemistry Key Labo- \\ ratory, Advanced Materials Research Center of Wenzhou, Wenzhou University, Wenzhou, China; ${ }^{3}$ Shimadzu International Trading \\ (Shanghai) Co., Ltd., Guangzhou, China. \\ Email: ${ }^{*}$ mjh820@ustc.edu
}

Received September $10^{\text {th }}, 2011$; revised October $25^{\text {th }}, 2011$; accepted November $6^{\text {th }}, 2011$.

\begin{abstract}
A novel and simple route for synthesizing nanocrystalline ceramic powders in molten salt was introduced in the paper. Titanium carbide $(\mathrm{TiC})$ was prepared via the reaction of metallic magnesium powders with titanium dioxide $\left(\mathrm{TiO}_{2}\right)$, carbon source and molten salt in an autoclave at $650^{\circ} \mathrm{C}$. Carbon source (oxalic acid and citric acid) in this paper was stable, low toxic and cheap. X-ray powder diffraction $(X R D)$ patterns indicated that the products were cubic TiC. Scanning electron microscopy (SEM) images showed that the samples consisted of particles with an average size of 200 $\mathrm{nm}$ and $100 \mathrm{~nm}$ in diameter, respectively. Energy Dispersive Spectrometer (EDS) analysis of the samples suggested the products contained carbon and titanium elements. The product was also studied by the thermogravimetric analysis (TGA). It had good thermal stability and oxidation resistance below $350^{\circ} \mathrm{C}$ in air.
\end{abstract}

Keywords: Titanium Carbide, Chemical Synthesis, X-Ray Diffraction, Scanning Electron Microscopy

\section{Introduction}

It is known that transition metal carbides have found extensive applications in many fields, such as cutting tools, wear-resistant parts and high-temperature structural materials because of their outing properties, such as high hardness, high melting point, high thermal conductivity, high strength even at high temperatures, high wear and corrosion resistance, and a high degree of chemical stability [1-3]. Recently, much attention has been paid to their catalytic properties because they exhibit activities similar to those of the noble metals [4].

Titanium carbide (TiC) is one of the most important compounds among transition metal carbides, due to its promising physical and chemical properties, such as a high melting temperature $\left(3140^{\circ} \mathrm{C}\right)$, a high boiling temperature $\left(4820^{\circ} \mathrm{C}\right)$, high Vickers hardness $(28-35 \mathrm{GPa})$, high Young's modulus (410 - $450 \mathrm{GPa})$, low density $\left(4.93 \mathrm{~g} \cdot \mathrm{cm}^{-3}\right)$, high flexure strength $\left(240-400 \mathrm{~N} / \mathrm{mm}^{2}\right)$, good thermal conductivity $\left(21 \mathrm{~W} / \mathrm{m}^{2} \times \mathrm{K}\right)$, high resistance to corrosion and oxidation, high abrasion resistance, and high thermal shock resistance [5-8]. So it is widely used for cutting materials, abrasive, anti-wear and aerospace materials [9-11]. At the same time, it can also be used as a substitute for tungsten carbide in cermets because they have similar properties of high hardness and wear resistance, what's more, nickel is used as binder for $\mathrm{TiC}$ is cheaper and less toxic than cobalt which $\mathrm{WC}$ requires as a binder [12]. Because of the promising properties and extensive application of $\mathrm{TiC}$, it is meaningful to synthesize nanocrystalline $\mathrm{TiC}$ in a simple route at low temperature and with convenient manipulations.

Traditionally, TiC powders are commercially synthesized via the reaction of titanium dioxide and carbon in the temperature range of $1700^{\circ} \mathrm{C}-2300^{\circ} \mathrm{C}$ for $10-24 \mathrm{~h}$ [13], it is important to develop new technics to replace the old method which wastes time and energy. Recently, some new methods have been used to synthesize titanium carbide. Chandra et al. [14] synthesized nano-TiC powder using titanium gel precursor and carbon particles in the range of $1300^{\circ} \mathrm{C}-1580^{\circ} \mathrm{C}$ for $2 \mathrm{~h}$ under argon cover. 
Qi et al. [15] reported that nanowires $\mathrm{TiC}$ was also successfully synthesized by the reaction of $\mathrm{TiO}$ gas with methane in the presence of a catalyst containing Fe. Tong et al. [16] reported the thermal plasma method to synthesize nano-powders $\mathrm{TiC}$ with the average size of the $\mathrm{TiC}$ powders is less than $100 \mathrm{~nm}$. Lee et al. [17] reported nano-structured $\mathrm{TiC}$ was synthesized by liquid-magnesium reduction of vaporized $\mathrm{TiCl}_{4}+\mathrm{CCl}_{4}$ solution. David et al. [18] reported high surface area, porous titanium carbide (TiC) films have been synthesized employing physical vapor deposition of titanium at glancing angles under high vacuum within an ethylene ambient. Patel et al. [19] reported Silicon-based nanocomposites containing TiC were synthesized by high-energy mechanical milling (HEMM).

In this paper, we have developed a new convenient route to synthesize nanocrystalline $\mathrm{TiC}$ in the autoclave by the reaction of metallic magnesium powders with $\mathrm{TiO}_{2}$ and carbon source (oxalic acid $\left(\mathrm{C}_{2} \mathrm{H}_{2} \mathrm{O}_{4}\right)$ and citric acid $\left(\mathrm{C}_{6} \mathrm{H}_{8} \mathrm{O}_{7}\right)$, separately.) in an autoclave at $650^{\circ} \mathrm{C}$. In this route, $\mathrm{TiO}_{2}$ is more stable and safe in operation than other titanium source (e.g. $\mathrm{TiCl}_{4}$ ) and metallic magnesium powders as reductant are also more safe and convenient than other reductants (e.g. metallic sodium). Due to the whole synthesis route that is carried out in the sealed autoclave, so it can be obtained that all manipulations are rather safe and convenient.

\section{Experimental}

TiC was synthesized by a novel method. All chemicals were analytical grade and used without further purification. Initially, $\mathrm{TiO}_{2}$, metallic magnesium powders (excessive) and carbon source (oxalic acid $\left(\mathrm{C}_{2} \mathrm{H}_{2} \mathrm{O}_{4}\right)$ and citric acid $\left(\mathrm{C}_{6} \mathrm{H}_{8} \mathrm{O}_{7}\right)$, separately), $\mathrm{NaCl}$ and $\mathrm{MgCl}_{2}$ were put into a mortar orderly with continuous stirring. Then the mixture was transferred to a stainless steel autoclave that was heated at $650^{\circ} \mathrm{C}$ under argon atmosphere and then cooling to room temperature naturally. The product was collected and washed with dilute $\mathrm{HCl}$, distilled water, and absolute ethanol several times to remove all impurity species and then dried in vacuum at $60^{\circ} \mathrm{C}$ for $8 \mathrm{~h}$. Black powders were obtained.

The obtained samples were analyzed by powder X-ray diffraction (XRD) on a Bruker D8 Advance X-ray powder diffractometer using $\mathrm{Cu} \mathrm{K}-\alpha$ radiation (wave-length $\lambda$ $=1.54178 \AA$ ). 2 theta angles were from $30^{\circ}$ to $90^{\circ}$. The morphologies and EDS analysis of the samples were observed from a JEOL JSM-6700F scanning electron microscope.

\section{Results and Discussion}

Figure 1 shows the XRD patterns of the as-prepared

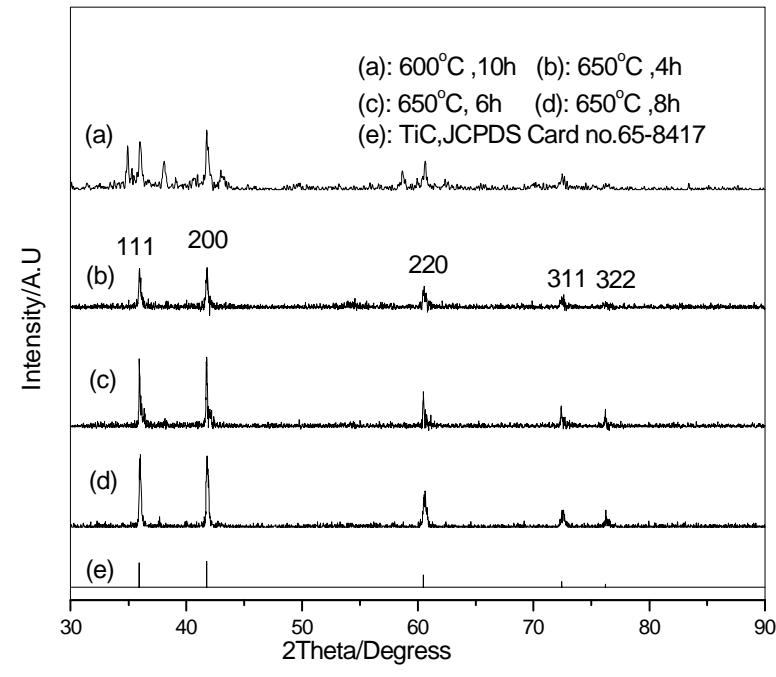

Figure 1. XRD patterns of the as-prepared samples (oxalic acid as carbon source) and standard pattern.

samples using oxalic acid as carbon source and TiC (JCPDS Card no. 65-8417). Pattern (a) shows the sample prepared under the condition of $600^{\circ} \mathrm{C}$ and $10 \mathrm{~h}$. Obviously, the sample is not purity with other matters. Pattern (b), Pattern (c) and Pattern (d) show that the samples are prepared under the condition of $650^{\circ} \mathrm{C}$ and $4 \mathrm{~h}, 6 \mathrm{~h}$ and $8 \mathrm{~h}$, respectively. There are five obvious diffraction peaks in these patterns. And all these diffraction peaks (( $\left.\begin{array}{lll}1 & 1 & 1\end{array}\right),(2$

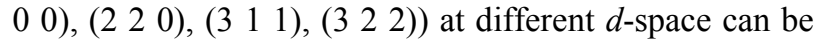
indexed as cubic titanium carbide (TiC). The refinement gives the cell constants $(a=b=c=4.326 \AA)$, which is consistent with the value reported in the literature $(a=b$ $=c=4.325 \AA$ ) (JCPDS card no. 65-8417). No evidences of impurities such as titanium, titanium dioxide, other titanium carbides, can be found in these XRD patterns.

Figure 2 shows the XRD patterns of the as-prepared samples using citric acid as carbon source and $\mathrm{TiC}$ (JCPDS Card no. 65-8808). Pattern (a) shows the sample was prepared under the condition of $650^{\circ} \mathrm{C}$ and $4 \mathrm{~h}$, there are five obvious diffraction peaks in this pattern. And all these diffraction peaks (( $\left.\begin{array}{lll}1 & 1 & 1\end{array}\right),\left(\begin{array}{lll}2 & 0 & 0\end{array}\right),\left(\begin{array}{lll}2 & 2 & 0\end{array}\right),\left(\begin{array}{lll}3 & 1 & 1\end{array}\right)$, (3 22 2)) at different $d$-space can be indexed as cubic titanium carbide (TiC). The refinement gives the cell constants $(a=b=c=4.3213 \AA)$, which is consistent with the value reported in the literature $(a=b=c=4.316$ $\AA$ ) (JCPDS card no. 65-8808). No evidences of impurities such as titanium, titanium dioxide, other titanium carbides, can be found in this XRD pattern.

The morphologies of the prepared $\mathrm{TiC}$ samples were investigated by field emission scanning electron microscopy. Figure 3(a), (b), (c) showed the SEM images of the as-prepared samples using oxalic acid, which were prepared under the reaction conditions of $650^{\circ} \mathrm{C}$ and $4 \mathrm{~h}$, 


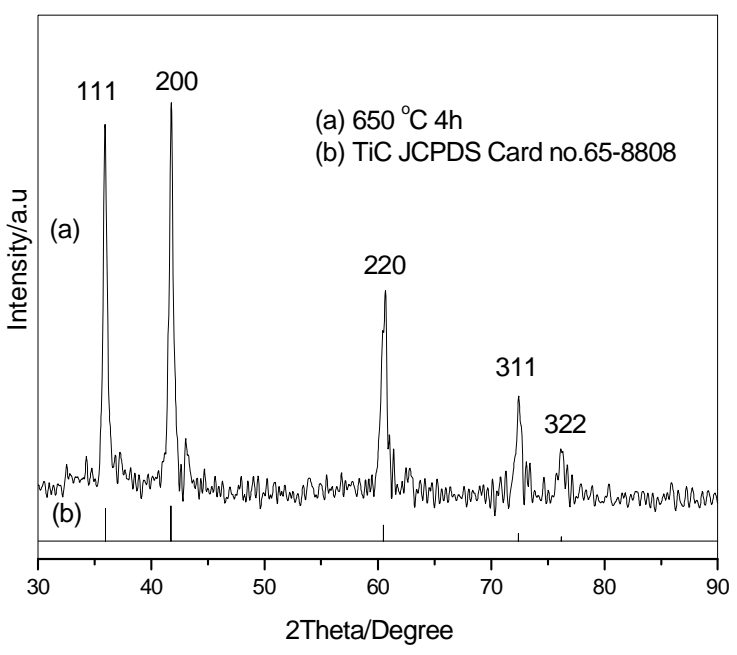

Figure 2. XRD patterns of the as-prepared samples (citric acid as carbon source) and standard pattern.
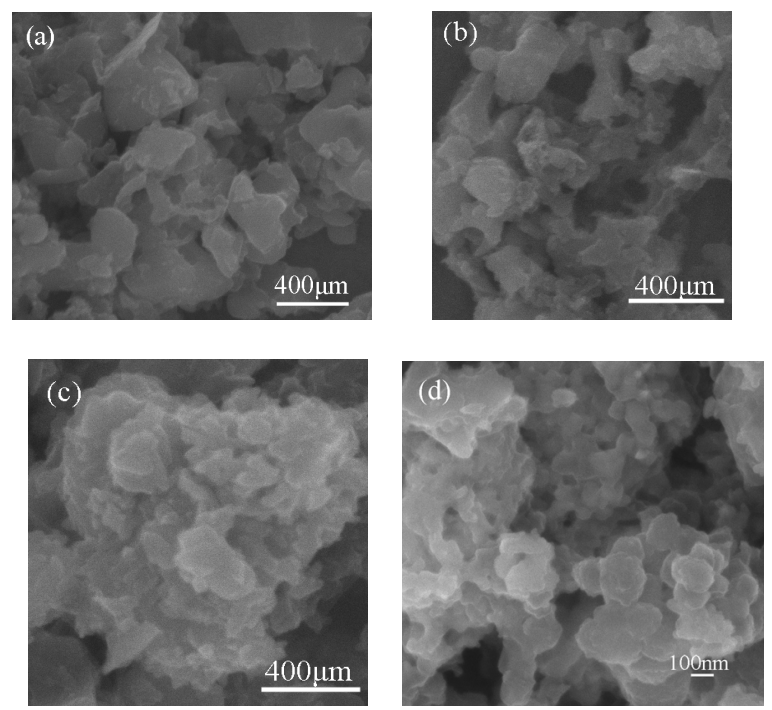

Figure 3. SEM images of the as-prepared samples prepared under different reaction conditions ((a), (b) and (c) samples using oxalic acid, (d) sample using citric acid): (a) $650^{\circ} \mathrm{C}, 4$ h; (b) $650^{\circ} \mathrm{C}, 6 \mathrm{~h}$; (c) $650^{\circ} \mathrm{C}, 8 \mathrm{~h}$; (d) $650^{\circ} \mathrm{C}, 4 \mathrm{~h}$.

$6 \mathrm{~h}, 8 \mathrm{~h}$, respectively. The samples showed that they consisted of particles with an average diameter of $200 \mathrm{~nm}$. It seemed not to affect the particle size of the samples significantly, through varying the reaction time at the temperature of $650^{\circ} \mathrm{C}$. Figure 3(d) showed the SEM image of the as-prepared sample using citric acid, which was prepared under the reaction conditions of $650^{\circ} \mathrm{C}$ and $4 \mathrm{~h}$. The sample showed that it consisted of particles with an average diameter of $100 \mathrm{~nm}$. The reaction temperature of the $\mathrm{TiC}$ samples prepared using oxalic acid and citric acid as carbon source is $650^{\circ} \mathrm{C}$. They maybe have potential for the economy and efficiency of synthesis of $\mathrm{TiC}$ nanopowders for industrial applications. Compared to citric acid as carbon source, the size of the particles prepared using oxalic acid as carbon source shows increase. These particles exhibit slightly agglomerated particle morphology due to the ultrafine size of the sample.

The EDS figures of the prepared TiC samples were shown in the Figure 4 and Figure 5. The EDS images of the as-prepared $\mathrm{TiC}$ samples were prepared under differrent reaction conditions. Figure $\mathbf{4}$ showed the sample was prepared under the condition of $650^{\circ} \mathrm{C}$ and $4 \mathrm{~h}$ using oxalic acid as carbon source, and Figure 5 showed the sample was prepared under the condition of $650^{\circ} \mathrm{C}$ and 4 $\mathrm{h}$ using citric acid as carbon source. According to the EDS results, the products are composed of $\mathrm{C}$, Ti, $\mathrm{Zn}, \mathrm{Cu}$ elements, without the contamination of oxygen. Both $\mathrm{Zn}$ and $\mathrm{Cu}$ come from the copper plateform. It can be concluded that the selectional particulates may be TiC. It can be found that $\mathrm{TiC}$ particulates in a great measure are 200 $\mathrm{nm}$ and $100 \mathrm{~nm}$, respectively. Furthermore, the weight percentage of Titanium and carbon analyzed by EDS

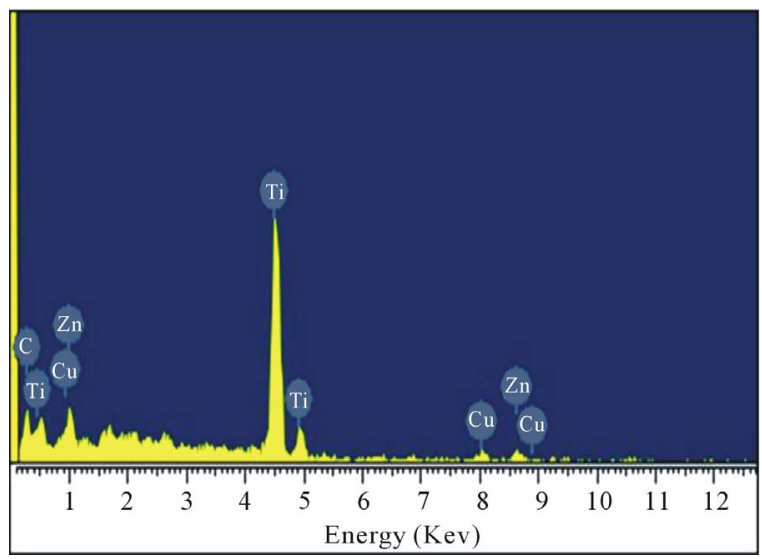

Figure 4. EDS of the sample prepared under the condition of $650^{\circ} \mathrm{C}$ and $4 \mathrm{~h}$ using oxalic acid as carbon source.

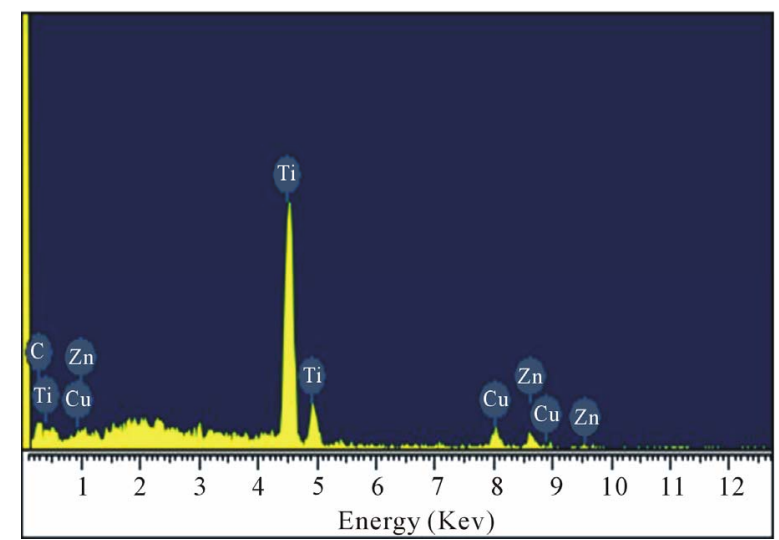

Figure 5. EDS of the sample prepared under the condition of $650^{\circ} \mathrm{C}$ and $4 \mathrm{~h}$ using citric acid as carbon source. 
were 55.63:17.90 in the Figure 4 and 60.73:23.29 in the Figure 5; while the atomic ratio of Titanium and carbon were $0.77: 1.00$ and $0.66: 1.00$, separately.

We are in order to investigate the thermal stability and the oxidation resistance of the as-prepared $\mathrm{TiC}$ powders using oxalic acid that they were prepared under the condition of $650^{\circ} \mathrm{C}$ and $8 \mathrm{~h}$ by the thermogravimetric analysis (TGA), which was carried out at temperatures below $1000^{\circ} \mathrm{C}$ under flowing air and nitrogen gases. We can find that the weight of the product has changed slightly below $400^{\circ} \mathrm{C}$. A weight loss indicates that the sample might adsorb a little water on the surface. In this stage, the sample is very stable. After about $400^{\circ} \mathrm{C}$, TiC sample is found to begin slowly oxidized, which indicates that the sample is oxidized by oxygen to form titanium oxide and carbon dioxide, titanium oxides, both stoichiometric and nonstoichiometric $\left(\mathrm{TiO}_{2}, \mathrm{Ti}_{3} \mathrm{O}_{5}, \mathrm{Ti}_{2} \mathrm{O}_{3}, \mathrm{TiO}\right)$ may be formed during the oxidation process. We can conclude from the curve of Figure 6 that more quantity of titanium oxide should be increased along with further oxidation. As the temperature rises from $400^{\circ} \mathrm{C}$ to $850^{\circ} \mathrm{C}$, there is an obvious weight gain during the process, indicating that the TiC sample is oxidized into titanium oxide and carbon dioxides. Between $850^{\circ} \mathrm{C}$ and $920^{\circ} \mathrm{C}$, the carbon dioxide generated in the simple surface slowly released may induce a small weight loss. Above $920^{\circ} \mathrm{C}$, the weight gain remains almost constant. We also can find that the weight of the product has changed slightly below $1000^{\circ} \mathrm{C}$ under flowing nitrogen gases, this is because that the sample might adsorb nitrogen gases on the surface.

It was suggested that reaction temperature had a significant influence on the formation of TiC. The XRD patterns of the as-prepared samples were synthesized under different temperature, time conditions and different car-

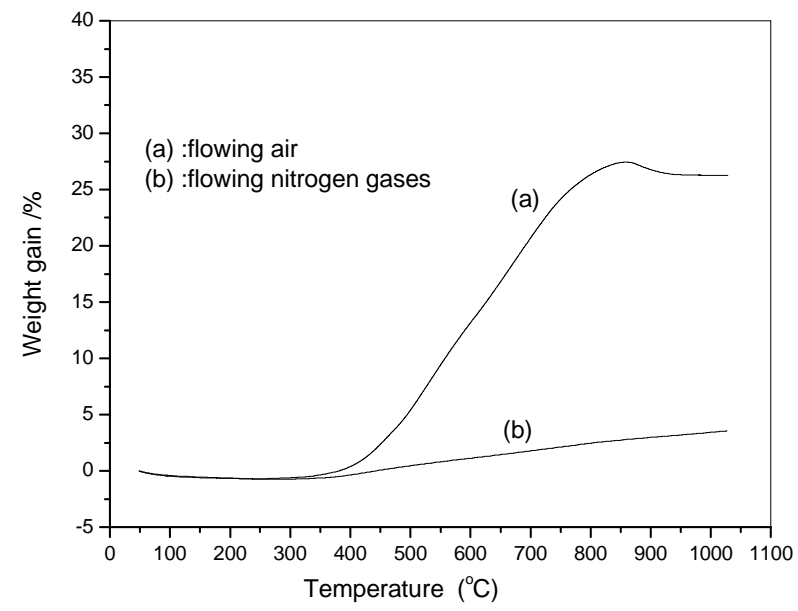

Figure 6. TGA curves in flowing air and nitrogen gases of the as-prepared TiC sample using oxalic acid prepared under the condition of $650^{\circ} \mathrm{C}$ and $8 \mathrm{~h}$. bon source. The SEM images of these samples are shown in Figure 3. From the XRD patterns, we can easily obtain conclusion that $\mathrm{TiC}$ could be synthesised when the reaction temperature is $600^{\circ} \mathrm{C}$, but the crystallinity is not very good, and has some impurities such as Ti can be found in the Figure 1(a). When the temperature is $650^{\circ} \mathrm{C}$, the crystallinity of the sample is very good, and no evidences of crystal impurities such as titanium, titanium oxides, other titanium carbides, can be found in these XRD patterns. An optimum temperature for the formation of nanocrystalline $\mathrm{TiC}$ is about $650^{\circ} \mathrm{C}$. Varying the reaction time at $650^{\circ} \mathrm{C}$ did not significantly affect the particle size of the as-prepared TiC shown in Figure 3(a)(c). However, the carbon source in the reaction processes can affect the size of the products. Compared to citric acid as carbon source, the size of the particles prepared using oxalic acid as carbon source shows increase.

In our experiments, as the temperature rising, $\mathrm{C}_{2} \mathrm{H}_{2} \mathrm{O}_{4}$ and $\mathrm{C}_{6} \mathrm{H}_{8} \mathrm{O}_{7}$ could decompose generating carbon oxides gases. So the pressure in the autoclave may be very high. The high pressure in the autoclave would be helpful for reducing the reaction temperature and enhancing the reaction speed. At the reaction temperature, $\mathrm{TiO}_{2}$, carbon oxides gases and metallic magnesium powders could react with each other to produce cubic TiC. The total reaction process can be represented as the following:

$$
\begin{gathered}
2 \mathrm{TiO}_{2}+10 \mathrm{Mg}+\mathrm{C}_{2} \mathrm{H}_{2} \mathrm{O}_{4} \cdot 2 \mathrm{H}_{2} \mathrm{O} \rightarrow 2 \mathrm{TiC}+10 \mathrm{MgO}+3 \mathrm{H}_{2} \\
\mathrm{C}_{6} \mathrm{H}_{8} \mathrm{O}_{7}+19 \mathrm{Mg}+6 \mathrm{TiO}_{2} \rightarrow 6 \mathrm{TiC}+19 \mathrm{MgO}+4 \mathrm{H}_{2}
\end{gathered}
$$

\section{Conclusions}

In summary, nanocrystalline cubic $\mathrm{TiC}$ has been prepared via a simple thermal route by the reaction of metallic magnesium powders with titanium dioxide $\left(\mathrm{TiO}_{2}\right)$ and carbon source (oxalic acid and citric acid) in molten salt at $650^{\circ} \mathrm{C}$ for $4 \mathrm{~h}$. The product crystalline structure is cubic. It consists of particles with an average size of 200 $\mathrm{nm}$ and $100 \mathrm{~nm}$, respectively. Compared to other carbon source (e.g. $\mathrm{CCl}_{4}$ ), carbon source in this paper is stable, low toxic and cheap, it can be obtained that all manipulations are rather safe and convenient. This simple chemical synthesis route maybe provide a new method to prepare other transition metal carbides.

\section{Acknowledgements}

This work was supported by Innovation and Promotion of science-technology project of Zhejiang Province and Department of Education of Zhejiang Province of China under Grant No. 20070546.

\section{REFERENCES}

[1] E. K. Stroms, "The Refractory Carbides, Refractory Ma- 
terials Series,” Academic Press, New York, 1967.

[2] L. E. Toth, "Transition Metal Carbides and Nitrides," Academic Press, New York, 1971.

[3] H. O. Pierson. "Handbook of Refractory Carbides and Nitrides," Noyes Publications, Park Ridge, 1996.

[4] M. Nagai, T. Miyao and T. Tuboi, "Hydrodesulfurization of Dibenzothiophene on Alumina-Supported Molybdenum Nitride," Catalysis Letters, Vol. 18, No. 1-2, 1993, pp. 914. doi:10.1007/BF00769493

[5] J. J. Gangler, "Some Physical Properties of Eight Refractory Oxides and Carbides," Journal of the American Ceramic Society, Vol. 33, No. 12, 1950, pp. 367-374. doi:10.1111/j.1151-2916.1950.tb14155.x

[6] Y. Shin, X. S. Li, C. Wang, J. R. Coleman and G. R. Exarhos, "Synthesis of Hierarchical Titanium Carbide from Titania-Coated Cellulose Paper," Advanced Materials, Vol. 16, No. 14, 2004, pp. 1212-1215. doi:10.1002/adma.200306661

[7] G. Yasuo, F. Kensaku, K. Mikio, O. Yutaka, N. Masanobu and A. Kensuke, "Synthesis of Titanium Carbide from a Composite of $\mathrm{TiO}_{2}$, Nanoparticles/Methyl Cellulose by Carbothermal Reduction," Material Research Bulletin, Vol. 36, No. 13-14, 2001, pp. 2263-2275. doi:10.1016/S0025-5408(01)00713-9

[8] P. Huber, D. Manova, S. Mandl and B. Rauschenbach, "Formation of TiN, TiC and TiCN by Metal Plasma Immersion Ion Implantation and Deposition," Surface and Coatings Technology, Vol. 174-175, 2003, pp. 1243-1247. doi:10.1016/S0257-8972(03)00458-4

[9] S. C Tjong and Z. Y. Ma, "Microstructural and Mechanical Characteristics of in Situ Metal Matrix Composites," Materials Science and Engineering: R: Reports, Vol. 29, No. 3-4, 2000, pp. 49-113. doi:10.1016/S0927-796X(00)00024-3

[10] N. Durlu, "Titanium Carbide Based Composites for Hightemperature Applications," Journal of the European Ceramic Society, Vol. 19, No. 13-14, 1999, pp. 2415-2419. doi:10.1016/S0955-2219(99)00101-6

[11] P. Ettmayer, H. Kolaska, W. Lengauer and K. Dreyer, "Ti(C,N)-Metallurgy and Properties," International Jour- nal of Refractory Metals and Hard Materials, Vol. 13, No. 6, 1995, pp. 343-351. doi:10.1016/0263-4368(95)00027-G

[12] R. Koc and J. S. Folmer, "Carbothermal Synthesis of Titanium Carbide Using Ultrafine Titania Powders," Journal of Materials Science, Vol. 32, No. 12, 1997, pp. 31013111. doi:10.1023/A:1018634214088

[13] N. A. Hassine, J. G. P. Binner and T. E. Cross, "Synthesis of Refractory Metal Carbide Powders via Microwave Carbothermal Reduction," International Journal of Refractory Metals and Hard Materials, Vol. 13, No. 6, 1995, pp. 353-358. doi:10.1016/0263-4368(95)00035-H

[14] C. Navin, S. Meenakshi, S. D. Kumar and S. S. Amritphale, "Synthesis of Nano-TiC Powder Using Titanium Gel Precursor and Carbon Particles," Materials Letters, Vol. 63, No. 12, 2009, pp. 1051-1053. doi:10.1016/j.matlet.2009.02.004

[15] S. R. Qi, X. T. Huang, Z. W. Gan, X. X. Ding and Y. Cheng, "Synthesis of Titanium Carbide Nanowires," Journal of Crystal Growth, Vol. 219, No. 4, 2000, pp. 485-488. doi:10.1016/S0022-0248(00)00634-5

[16] L. Tong and G. R. Ramana, "Synthesis of Titanium Carbide Nano-Powders by Thermal Plasma," Scripta Materialia, Vol. 52, No. 12, 2005, pp. 1253-1258. doi:10.1016/j.scriptamat.2005.02.033

[17] D. W. Lee and B. K. Kim, "Synthesis of Nano-Structured Titanium Carbide by Mg-Thermal Reduction," Scripta Materialia, Vol. 48, No. 11, 2003, pp. 1513-1518. doi:10.1016/S1359-6462(03)00130-1

[18] D. W. Flaherty, N. T. Hahn, D. Ferrer, R. E. Todd, L. T. Paul and M. C. Buddie, "Growth and Characterization of High Surface Area Titanium Carbide," The Journal of Physical Chemistry C, Vol. 113, No. 29, 2009, pp. 1274212752. doi:10.1021/jp904236v

[19] P. Patel, S. Kim II and P. N. Kumta, "Nanocomposites of Silicon/Titanium Carbide Synthesized Using High- Ener- gy Mechanical Milling for Use as Anodes in Lithium-Ion Batteries," Materials Science and Engineering B, Vol. 116, No. 3, 2005, pp. 347-352. doi:10.1016/j.mseb.2004.05.046 